\title{
Smoking And Thiocyanates In High School Students, University Students And Children With Hypertension
}

\author{
Angelova $\mathrm{M}^{1}$, Kolarova-Yaneva $\mathrm{N}^{2}$, Nikolov $\mathrm{A}^{3}$, Nedkova $\mathrm{V}^{2}$ \\ ${ }^{1}$ Department "Chemistry and biochemistry \& physics and biophysics", Section "Chemistry", Medical University, \\ Pleven, Bulgaria \\ ${ }^{2}$ Department of Pediatrics, Medical University, Pleven, Bulgaria \\ ${ }^{3}$ Department of Propedeutics of Internal Diseases, Medical University, Pleven, Bulgaria
}

\begin{abstract}
SUMMARY:To objectify smoking and its connection with various diseases and conditions are used analytical markers. The aim of our study was to estimate smoking and its intensity by determination of thiocyanates in blood serum and / or urine at high school students, university students and children with essential hypertension / PAH /. In the group of children with high blood pressure (BP) were also determined lipid parameters. Thiocyanates are determined in the urine of 86 students aged 15-18 years, and 10-15 year olds 41 hypertensive. 84 medical students - 18-22 years old were studied serum and urine thiocyanate. We found that $44.49 \%$ of students and $50 \%$ of students are smokers, and $47.4 \%$ of smokers and $50 \%$, respectively smoke more than 10 cigarettes a day.The differences in thiocyanates levels in serum and urine in the groups of non-smokers, smoking 10 cigarettes a day and smoking more than 10 cigarettes a day students are statistically significant. Children with hypertension smokers are 31.02\%. They have statistically higher levels of thiocyanates in urine, higher values of cholesterol and triglycerides and lower HDL-cholesterol, compared to non - smokers with hypertension.The results supported by published data shows the relationship between smoking, high BP and lipid profile in infancy. Given that smoking not only affects the cardiovascular system and overall development of the child's body, it is necessary to introduce health programs and strategies for family life improvement, for prevention of smoking at school age and to provide support to those who want to quit smoking.
\end{abstract}

KEY WORDS:; smoking, thiocyanate, hypertension, children.

\section{INTRODUCTION}

Information for statistical evaluation of smoking is often gathered by surveys. Their results depend on many factors and are not always reliable. To objectify smoking assessment quantitative analytical criteria are used to distinguish smokers from non-smokers, determine the intensity of smoking or are used in the process of treatment.The markers that are most commonly used are carbon monoxide $(\mathrm{CO}, \mathrm{COHb})$, nicotine ( in plasma or serum, saliva , urine, hair, nails ), cotinine (plasma, saliva , urine, hair ), thiocyanates (plasma, saliva , urine ) (1-3).Practically suitable are the methods based on defining thiocyanates, which are metabolites of cyanide from tobacco smoke. Thiocyanates have - long half-life - 14 days which excludes false negative results in case of smoking interruption for over two days (3). Thiocyanates are also received endogenously with certain foods, so for their determination it is necessary to have a control group of non-smokers. Smoking damages the body of both active smokers and passive smokers. Unfortunately, smoking among adolescents and children becomes more and more frequent. The peak of early smoking is shifting from 18 years to 14-16 years of age, and smoking attempts were observed in the first decade of life for some of the children. Smoking in adults leads to cardiovascular disease (CVD), cerebrovascular, and respiratory diseases. Smoking affects the neuro-psychical functions by reducing the protective functions of the immune system (3-7). Smoking in adolescence sets the risk of developing these diseases in adulthood.Many of the traditional risk factors for CVD, such as high blood pressure, dyslipidemia, tobacco use, unhealthy diet and obesity begin in childhood. Prophylactic determination of these risk factors could prevent CVD (8). It is considered that smoking affects the increasing spread of the GCC and increases the risk of death by $20 \%$ (9). Studies, most often in adult populations show a relationship between smoking and arterial endothelial dysfunction, lipid parameters and onset of arterial hypertension and atherosclerosis. $(5,8)$. Therefore, the aim of our survey was to study smoking and its intensity by the usage of thiocyanate markers in blood serum and / or urine in school children, students and children with hypertension - one of the risk factors for CVD. In the group of children with elevated blood pressure (BP) lipid parameters were also identified. 


\section{METHODS}

\section{Focus and methods of the study:}

A research on thiocyanates in urine - a marker for smoking is presented In this study. It was conducted among 86 healthy students between 15-18 years of age on a voluntary basis. Determination of thiocyanates in blood serum and urine was also conducted among 84 clinically healthy medical students aged 18 to 22 years. 41 children aged 10 to 15 years with hypertension divided into two groups - smokers and nonsmokers were also tested. Throughout the study was completed a survey for the presence of family history. The method of determination of thiocyanates in urine and blood serum allows additional use of markers to distinguish smokers from non-smokers and to establish the intensity of smoking. Therefore, this research can be divided into three groups: non-smokers, a control group smoking 10 cigarettes per day and smoking more than 10 cigarettes a day. After children and their parents signed the informed consent morning venous blood samples $(5 \mathrm{ml})$ and urine were collected for quantitative determination of thiocyanates in serum and urine.

\section{Thiocyanates - quantitative criterion for smoking and its intensity}

The concentration of thiocyanate in biological samples can be determined by different methods gravimetric , titrimetric , electrochemical , kinetic, chromatographic, atomic , Roentgen , spectrophotometric (2, 10-12)To determine the concentration of thiocyanates in blood serum and urine we applied our modified spectrophotometric method Giraudi and Grillo (10), which allows the biomarker to be determined in two biodegradables - urine and blood serum. Lower limit of detection of the method allows to reduce the volume of samples analyzed and the volumes of reagents used. Study relative standard deviation (RSD\% - Relative Standard Deviation) showed good reproducibility of the method 2:04 to 6:00\%. The method is fast and its technical execution is easy - requires the addition of only two reagents to the pre-treated samples, which makes it applicable for serial analyzes. Indicator for the relevance of the method is the data collected from the literature review - the method of Giraudi and Grillo is one of the most quoted and used spectrophotometric methods $(11,12)$.

\section{Determination of thiocyanates in urine and blood serum}

A pre -treatment of samples is carried out before the analysis: In dry test tubes with stoppers are mixed urine and $0,25 \mathrm{ml} 1 \mathrm{ml}$ of acetate buffer $\mathrm{pH} 4.1$,bidistilled water is added up to a volume of $5 \mathrm{ml}$ and was homogenized well .In dry centrifuge tubes are mixed $0.5 \mathrm{ml}$ of blood serum, $0.25 \mathrm{ml} 0.08 \mathrm{~mol} / 1$ solution of sodium perchlorate and $0.25 \mathrm{ml}$ of $20 \%$ trichloroacetic acid. After 15 minutes, the mixture is centrifuged $20 \mathrm{~min}$ at $2000 \mathrm{rev} / \mathrm{min}$. Then, in the tube is transferred $0.5 \mathrm{ml}$ of the clear solution and are sequentially added, and $0.5 \mathrm{ml} 1 \mathrm{mo} 1 / 1$ sodium hydroxide solution and $5 \mathrm{ml}$ of doubly distilled water. The contents of the tube are homogenized.Analytical procedure for the determination of thiocyanates is brief: to $1 \mathrm{ml}$ of diluted urine or serum sample, add $1 \mathrm{ml}$ reagent $\mathrm{K}(1: 1$ mixture of $1 \%$ xloramin $\mathrm{T}$ trihydrate $(\mathrm{C} 7 \mathrm{H} 7 \mathrm{CINaNO} 2 \mathrm{~S} \cdot 3 \mathrm{H} 2 \mathrm{O})$, and $0.1 \%$ ferric chloride $(\mathrm{FeCl} 3 \cdot 6 \mathrm{H} 2 \mathrm{O})$, and the mixture is homogenized for about $20-30 \mathrm{~s}$. Then it is added: 0,4 $\mathrm{ml}$ reagent $\mathrm{D}$ ( $6 \mathrm{~g}$ of barbituric acid $(\mathrm{C} 4 \mathrm{H} 4 \mathrm{~N} 2 \mathrm{O} 3), 64 \mathrm{~g}$ bidistilled water, $6 \mathrm{ml}$ of concentrated hydrochloric acid $(\mathrm{HCl}, \mathrm{d}=1,18)$ and again homogenization follows. After 15-20 min samples are spektrofotometrated (wavelength $605 \mathrm{~nm}$ ) into one centimeter cuvettes against double distilled water.The content of thiocyanates in the serum and urine is determined from a calibration graphic. To build the calibration schedule - absorption vs. concentration of thiocyanate to $1 \mathrm{ml}$ of the standard solution $(0,1 ; 0,3 ; 0,5 \mathrm{mg} / 1 \mathrm{SCN}-)$ are added to the reactants and $\mathrm{R}$ and $\mathrm{R}$, the absorbance as in the described above procedure for urine and serum samples . DR 2800 spectrophotometer of Hach Lange works under a computer program for the construction of calibration graphics. Electronically by the standard straight line, based on the values of the absorbance of the samples, the results for the concentration of thiocyanates are reported to the display in the specified units. Calibration chart is checked before each series of analyzes.

\section{Clinical methods}

Arterial blood pressure was measured using a standard mercury sphygmomanometer, to the nearest 2 $\mathrm{mm} \mathrm{Hg}$, in the dominant arm after at least $10 \mathrm{~min}$ of rest in supine position.Serum total cholesterol concentrations were measured by an enzyme spectrophotometric CHOD-PAP assay (Roche). Triglyceride concentrations were measured by an enzyme spectrophotometric GPO-PAP assay (Roche). HDL cholesterol was measured by an enzyme spectrophotometric assay for direct measurement with HDL-C plus (Roche). 


\section{Statistical analysis}

The survey data was processed with the statistical software package Statgraphics Plus (Manugistics, Rockville, MD) and EXCEL for Windows.The results are described and tabulated with numerical values (shares, structure, mean $(\mathrm{X})$, standard deviation (SD), correlation coefficients, etc.).In the analysis of the results parametric tests for verifying the hypotheses were applied using the t-test of Student and Analysis of Variance (ANOVA). The significance of the findings and conclusions were determined in reliability $\mathrm{q} \leq 0.05$ $(95 \%)$.

\section{RESULTS AND DISCUSSION}

\section{Smoking and thiocyanate in urine school students}

The studied in 86 healthy students on a voluntary basis the age 15-18 years data suggest that smoking is largely spread among the surveyed students - $44.49 \%$ of them were smokers and $47.4 \%$ of the smokers smoke more than 10 cigarettes a day.

Fig.1. Urinary thiocyanates in school students - smokers and a control group

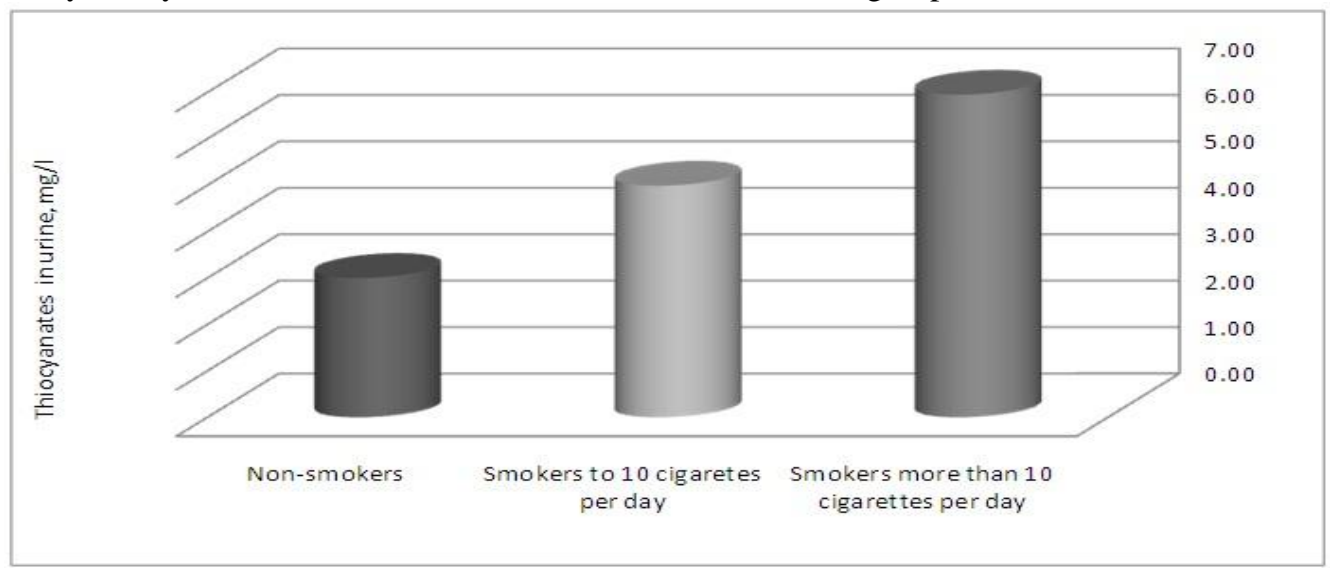

The values obtained for the concentration of thiocyanate in the urine ( Fig. 1 )

In non-smokers $(\mathrm{n}=48)$ were $3.00 \pm 1.41 \mathrm{mg} / \mathrm{l}(51.60 \pm 24.25 \mu \mathrm{mol} / \mathrm{l}) ;$ smokers up to $10 \mathrm{cig} / \mathrm{day}(\mathrm{n}=20)-$ $4.99 \pm 2.24 \mathrm{mg} / 1(85.83 \pm 38.53 \mu \mathrm{mol} / \mathrm{l})$ and smokers over 10 cigarettes per day $(\mathrm{n}=18)-6.95 \pm 2.36 \mathrm{mg} / 1$ ( $119 \pm 40.59 \mu \mathrm{mol} / 1)$.The differences between the groups were statistically significant with a confidence interval between smoking and smoking up to 10 cigarettes a day groups $\mathrm{p}<0.01$ and between smoking 10 cigarettes per day and smoking more than 10 cigarettes a day $\mathrm{p}<0.05$.

Thiocyanates in blood serum and urine in university students

A total of 84 clinically healthy medical students aged 18 to 22 years were tested. The results are presented in Table 1.

Table 1. Content thiocyanates - $\mathrm{mg} / 1(\mu \mathrm{mol} / \mathrm{l})$, urine and blood serum students

\begin{tabular}{|c|c|c|}
\hline Groups of students & $\begin{array}{l}\mathrm{SCN}-(\mathrm{x} \pm \mathrm{s})^{*}, \quad \mathrm{mg} / \mathrm{l}(\mu \mathrm{mol} / \mathrm{l}) \text { in } \\
\text { blood serum }(\text { number }=\mathrm{n})\end{array}$ & $\begin{array}{l}\mathrm{SCN}-(\mathrm{x} \pm \mathrm{s})^{*}, \mathrm{mg} / \mathrm{l}(\mu \mathrm{mol} / \mathrm{l}) \\
\text { in urine }(\text { number }=\mathrm{n})\end{array}$ \\
\hline $\begin{array}{l}\text { Smokers - } 10 \text { cigarettes a day } \\
\text { Smokers - more than } 10 \text { cigarettes } \\
\text { a day } \\
\text { Smoking-control group }\end{array}$ & $\begin{array}{l}3,78 \pm 1,52(65,02 \pm 26,14) \\
(\mathrm{n}=15) \\
8,36 \pm 3.58(143,79 \pm 61,58) \\
(\mathrm{n}=16) \\
1,41 \pm 0,69(24,25 \pm 11,87) \\
(\mathrm{n}=35)\end{array}$ & $\begin{array}{l}3,25 \pm 1,61(55,90 \pm 27,69) \\
(\mathrm{n}=23) \\
8,54 \pm 3,44(146,89 \pm 59,17) \\
(\mathrm{n}=19) \\
1,35 \pm 0,54(23.22 \pm 9,29) \\
(\mathrm{n}=42)\end{array}$ \\
\hline
\end{tabular}

Differences between groups smoking / smoking (10 cigarettes per day, and more than 10 cigarettes per day) were statistically significant with a significance level of $p=0.01(99.9 \%)$. The thiocyanates, blood serum and in urine results in the groups of smokers up to 10 of cigarettes a day / smokers over 10 cigarettes per day are with the same degree of statistical significance. 
The comparison of the results for the levels of thiocyanates in urine between the groups of smokers up to 10 cigarettes a day, smokers over 10 cigarettes a day, smokers among schoolchildren (15-18 years) and students (18-22 years) showed that the differences were not statistically significant . There is a trend of increased content of thiocyanates in urine for the students smoking more than 10 cigarettes a day, compared with the same group of.The total number of students tested for thiocyanates in urine is $84(100 \%)$ the number of smokers is $42(50 \%)$. In comparison, smokers are $44.49 \%$. This trend of increased number of student schoolchildren is alarming.

\section{Smoking and elevated blood pressure in childhood}

In a survey conducted in 337 children aged 10 to 15 years, $32.04 \%$ have indicated that are smokers and $67.56 \%$ have denied smoking. It was found that in this population, $6 \%$ of the children ( 22 children) are with increased AP and $31.02 \%$ from them smoke. The survey data also found that most often smoking starts at age 11-13 years - in $58.49 \%$ of the children with elevated blood pressure and in $74.19 \%$ of the total number of smokers included in the survey. $34 \%$ of the participants indicated that one of the parents is suffering from hypertension , $5 \%$ of the participants indicated both parents .In the group of children with hypertension it was found that $45 \%$ from them had family anamnesis for hypertension. Respondents reported no presence of other diseases.Table 2 presents the results of a study on blood pressure of thiocyanates in urine and lipid indicators separate from the inquiry group 41 children with hypertension diagnosed before 2 to 3 years $(2.42 \pm 0.52$ years).

Table 2. Blood pressure, $\mathrm{mmHg}$; concentration of thiocyanate in urine, $\mathrm{mg} / \mathrm{l}$ and lipid parameters in children with hypertension

\begin{tabular}{|c|c|c|c|}
\hline Indicators & Smokers $(n=16)$ & $\begin{array}{l}\text { Non-smokers } \\
(\mathrm{n}=25)\end{array}$ & $\begin{array}{c}\text { Statistical } \\
\text { authenticity, } p\end{array}$ \\
\hline Systolic pressure, $\mathrm{mmHg}$ & $150.61 \pm 5.66$ & $143.92 \pm 5.31$ & $<0.05$ \\
\hline Diastolic pressure, $\mathrm{mmHg}$ & $91.45 \pm 5.13$ & $89.92 \pm 2.81$ & $>0.10$ \\
\hline Thiocyanates in urine, $m g / l$ & $4.34 \pm 2.58$ & $1.90 \pm 0.46$ & $<0.001$ \\
\hline $\begin{array}{l}\text { Total cholesterol, mmol/l } \\
\text { (standard }<5.20 \mathrm{mmol} / \mathrm{l} \text { ) }\end{array}$ & $7.35 \pm 1.33$ & $4.79 \pm 1.28$ & $<0.001$ \\
\hline $\begin{array}{l}\text { triglycerides, } \mathrm{mmol} / \mathrm{l} \\
(\text { standard }<1.94 \mathrm{mmol} / \mathrm{l})\end{array}$ & $1.70 \pm 0.84$ & $1.22 \pm 0.39$ & $<0.05$ \\
\hline $\begin{array}{l}\text { HDL cholesterol mmol/1 } \\
\text { (standard }<0.90 \mathrm{mmol} / \mathrm{l} \text { ) }\end{array}$ & $0.94 \pm 0.23$ & $1.01 \pm 0.21$ & $<0.05$ \\
\hline $\begin{array}{l}\text { LDL cholesterol mmol/l } \\
\text { (standard <3.88 mmol/1) }\end{array}$ & $6.15 \pm 1.53$ & $4.35 \pm 1.44$ & $<0.05$ \\
\hline BMI, $\mathrm{kg} / \mathrm{m}^{2}$ & $18.60 \pm 1.20$ & $19.3 \pm 4.20$ & $>0.10$ \\
\hline
\end{tabular}

Surveyed smokers with hypertension, according to the questionnaire data smoke to 10 cigarettes a day. The results obtained for thiocyanates in urine confirmed the inquiry data.The results show a trend towards higher blood pressure in children smokers with hypertension. These results combined with higher levels of total cholesterol and triglycerides in children with hypertension smokers of the same children - smokers with hypertension.Tobacco use in the pediatric population leads to a reduction in cardiac function, and increase oxidative stress, which is associated with neposredsveno increase of triglyceride and cholesterol, and a reduction of high density lipoprotein (13) - results obtained in our study. In this respect we can say that smoking as one of the cardiovascular risk factors play a major role in the development of hypertension. Immediate harmful effects of smoking are associated with sympathetic nervous hyperactivity. This increases the oxygen consumption of the myocardium by increased blood pressure, heart rate and myocardial contractility. Cigarette smoking causes the arterial stiffness, which may persist for ten years after smoking cessation (13). Smoking has an adverse effect on the saturation of hemoglobin with oxygen and therefore distorts the oxygenation of the blood, stimulates the activity of nicotinic acetylcholine receptors, and indirectly affects the 
activity of dopamine and adrenergic receptors play an important role in both the level of SBP and DBP (14). Not without significance is the fact that the compounds of the smoke produced by a burning cigarette are potent platelet activators (15). The indirect mechanism of injury (exerted by the increased concentrations of carboxyhemoglobin) is mediated by carbon monoxide, which causes the rigidity of the arterial wall and an increase in blood pressure. Measurements of blood pressure are increase of the direct toxic action of carbon monoxide on endothelial and blood cells.A pathologist has been shown that fatty stains and plaques are in children and adolescents, indicating that the fundamentals of atherogenesis should be sought from childhood (16). Tobacco smoke provokes the development of fiber boards and fatty streaks in the aorta and coronary arteries precursors of atherosclerosis. It is assumed that the cardio - vascular changes in later life associated with these early changes in the vascular wall (17). Therefore, determining vascular, endothelial function is used for both research and clinical prognostic and diagnostic purposes.

Thiocyanates, in turn, reinforce the hypoxic effects determined by the carbon monoxide. The aromatic amines can cause toxic effects on the cardiovascular system, although they have little effect on blood pressure. In addition to increasing blood pressure, a few years after the onset of smoking in smokers documented irreversible changes in the arterial wall, and left ventricular dysfunction. (18).Therefore, the incidence of hypertension was increased in smokers, especially among those who smoke 15 or more cigarettes per day ( 13 , 19) . High blood pressure with smoking decreased left ventricular function in asymptomatic people (13).The significant reduction in the cardiac function as a result of smoking is associated with adverse changes in HDL and decreased physical activity in children (5).

\section{CONCLUSION}

In our study, according to the questionnaire data estimate hereditary factors influence high blood pressure in infancy.Early onset of smoking at the age 11-13 years was found in $74 \%$ of the total number of smokers in the survey.Through the survey of thiocyanate in blood serum and urine, we found a higher frequency and intensity of smoking among the groups of students. There is a worrying trend of increased content of thiocyanate in urine students smoked more than 10 cigarettes a day, compared with the same group of students were smokers. The values of thiocyanates in blood serum and urine are also associated with the occurrence of high blood pressure in childhood. In the surveyed students aged $10-15$, it was found that $6 \%$ had elevated BP, $31 \%$ of them smoke.The obtained quantitative and scientific results for the establishment of smoking and its intensity, allowing it to be classified as one of the major cardiovascular risk factors affecting both the vascular function and on the lipid profile in infancy. This requires the implementation of health programs and strategies for improving family life, for the prevention of smoking at school age, and to support the desires to quit smoking. As smoking is prevalent worldwide, the evidence for this topic are in the interest of both the scientific community and to all persons - smokers and non-smokers, in order to control smoking.

\section{REFERENCE}

[1] Jarvis MJ, Sims M, Gilmore A, Mindell J. (2012). Impact of smoke-free legislation on children's exposure to secondhand smoke: cotinine data from the Health Survey for England. Tob Control, 21(1):18-23

[2] . Buratti M, Xaiz D, Caravelliand G, Colombi A. (1997). Validation of urinary thiocyanate as a biomarker of tobacco smoking. Biomarkers, 2 (2):81-85

[3] Hongbing Wang, Michikazu Sekine, Hiroshi Yokokawa, Shimako Hamanishi, Michio Sayama, Yuchi Naruse, Hideaki Nakagawa, Sadanobu Kagamimori. (2012). Serum thiocyanate concentration as an indicator of smoking in relation to deaths from cancer. Environmental Health and Preventive Medicine 6(2):88-91

[4] Dunbar A, Gotsis W, Frishman W. (2013) Second-hand tobacco smoke and cardiovascular disease risk: an epidemiological review.Cardiol Rev. 21(2):94-100

[5] Prasad DS, Kabir Z, Dash AK, Das BC. (2009). Smoking and cardiovascular health: A review of the epidemiology, pathogenesis, prevention and control of tobacco. Indian J Med Sci; 63(11):520-33

[6] Morisano D, Wing VC, Sacco KA, Arenovich T, George TP. (2013). Effects of Tobacco Smoking on Neuropsychological Function in Schizophrenia in Comparison to Other Psychiatric Disorders and Non-psychiatric Controls. Am J Addict. 22(1):4653

[7] Tavilani H, Nadi E, Karimi J, Goodarzi MT. (2012). Oxidative stress in COPD patients, smokers, and non-smokers. Respir Care. 57 (12):2090-4

[8] Pradeep A. Praveen, Ambuj Roy, Dorairaj Prabhakaran (2013).Cardiovascular Disease Risk Factors: A Childhood Perspective. Indian J Pediatr., 80 (1): S3 - S12.

[9] Giorgos S. Metsios, Andreas D. Flouris,Manuela Angioi, and Yiannis Koutedakis . (2011).Passive Smoking and the Development of Cardiovascular Disease in Children: A Systematic Review.Cardiology Research and Practice, Volume 2011, Article ID 587650.

[10] Giraudi G, Grillo C. (1981). Direct spectrophotometric determination of thiocyanate in serum and urine with a continuous-flow analyzer. Analytica Chimica Acta, 128, 169-75

[11] Acebal, C.C., Sklenářová, H., Škrlíková, J., Šrámková, I., Andruch, V., Balogh, I.S., Solich, P. (2012) Application of DV-SIA manifold for determination of thiocyanate ions in human saliva samples. Talanta 96 107-112

[12] Demkowska, I., Polkowska, Z., Namieśnik, J. (2011). Non-invasive biological fluid matrices analysed to assess exposure to environmental tobacco smoke. .Journal of Exposure Science and Environmental Epidemiology 21 (6) 656-661 
[13] Virdis A, Giannarelli C, Neves MF, Taddei S, Ghiadoni L . (2010).Cigarette smoking and hypertension. Curr Pharm Des.;16 (23). $2518-25$

[14] Milam J.E.(1998). The risks of tobacco use, a message of parents and teens, American academic of pediatrics, 25(1) 71-80

[15] Barnoya J., Glantz S. A. (2005). Cardiovascular Effects of Secondhand Smoke. Circulation. $111: 2684-2698$

[16] Kuneva A. (2001). Arterial hypertension in childhood - diagnostic and therapeutic approach. Science cardiology, 2 (5); 6-14

[17] Caroline C. Geerts, Michiel L. Bots, Cornelis K. van der Ent, Diederick E. Grobbee and Cuno S. P. M. Uiterwaal (2012). Parental Smoking and Vascular Damage in Their 5-year-old Children. Pediatrics 129 (1); 45 - 54

[18] Aurelio Leone (2012). How and why chemicals from tobacco smoke can induce a rise in blood pressure. World J Pharmacol. 1(1): $10-20$

[19] Liu T, Tyndale RF, David SP, Wang H, Yu XQ, Chen W, Wen XZ, Chen WQ (2013).Association between daily cigarette consumption and hypertension moderated by CYP2A6 genotypes in Chinese male current smokers. J Hum Hypertens. 27(1):2430 